\section{EUROPEAN COLLABORATION}

\section{Projects Galore}

TechNologrcal cooperation among Europeans is taking a hammering - the air bus affair is just the latest of a number of disappointments among which ELDO is the classical example. But a series of proposals which is being put forward in spheres at once less controversial and less expensive than aviation and rocketry deserves a better fate. The proposals are embodied in the unpublished report of a working party to discuss the possibilities for scientific and technological cooperation within the EEC and between the EEC and other European countries. The working party has a chequered history (Nature, 221, 898; 1969). It began in October 1967 and was called the Maréchal group after its chairman, who was later replaced by Professor Pierre Aigrain of the Délégation Générale de la Recherche Scientifique in Paris. Last year the group downed tools after the French veto of British entry into the Six, because the Dutch and Italians felt the French attitude was not in the spirit of the aims of the working party. Last September they were persuaded to start again, and their report has now been approved by the Medium Term Economic Policy Committee of the EEC. It goes now to the European Council of Ministers.

Countries outside the EEC which have applied for entry were represented together with other interested countries such as Sweden and Switzerland. They were asked to investigate the scope for cooperation in data processing, telecommunications, new means of transport, oceanography, metallurgy, pollution (which includes noise pollution of the environment) and meteorology. Altogether forty-seven specific proposals are listed, costing $\$ 210$ million, and thirty-four of these are said to be sufficiently well understood for the European Council to be able to decide about them fairly soon. The list includes projects to develop a high speed computer, a European data processing institute and the use of software in various fields. A scheme for a network for data transmission between research centres, a European program library and committees for software standardization are said to be specific enough for the council to come to an immediate decision. In most cases, cooperation with countries outside the EEC is thought to be desirable and for one project at least-a design study for a 2,000 ton hovercraft-the importance of collaboration with Britain is mentioned. There are some projects, however, notably in metallurgy, where the report says collaboration with countries outside the EEC is not particularly desirable, presumably to protect specific industries within the community- the development of materials for desalination and steel pressure vessels for the chemical industry, for example.

What the European Council of Ministers now has to do is decide which of the projects to back. Then the question will be how to finance them and, the most awkward problem in European cooperative ventures, which countries are to get the contracts. Many of the projects in the report may be held up by the lack of the standardization of European company law. The meteorological sphere would seem to be a good area to start with, because of the international links which are already well established. But one of the three proposals in meteorology-a European weather satellite-is likely to be too bedevilled with European space politics for much progress to be made. The other proposals, a meteorological research centre and cooperation in the development, standardization and purchase of instruments, have a better chance of success.

\section{PHYSICS \\ Europe Meets}

NeARly a thousand physicists from most countries of a slightly enlarged Europe converged on. Florence after Easter to attend the inaugural meeting of the European Physical Society. The theme of the five day symposium was the growth points in physics. Those who went in the hope of learning a wealth of new physics may have been slightly disappointed, but, for those who saw this meeting as a chance to rub shoulders with some of the more illustrious European physicists and to gain some insight into the wider trends of the subject, the trip to Florence was well worth while. The general nature of the title was a deliberate gesture, according to the secretary of the European Physical Society, Professor Laurens Jansen, to give physicists the widest pretext for attending the inaugural meeting.

After two stimulating introductory papers, on the old days at the Cavendish Laboratory by Professor P. M. S. Blackett, and on physics in the twentieth century by Professor V. F. Weisskopf, the meeting got its teeth into discussing the future of five of the principal branches of physics. It soon became clear that the spectacular advances in astrophysics in recent years reflected the most obvious growth point of physics, and Dr A. Hewish and Dr D. W. Sciama from Cambridge University delivered a comprehensive account of the latest developments in this subject.

In such a conference, nobody, of course, will admit to not working in a growing branch of the subject. but the general impression was that the nuclear physicists, who are ever eager to reach into the taxpayer's pocket for a new accelerator, gave a good account of themselves. If the mood of Florence is typical, and there was a large representation of nuclear physicists at the meeting, high energy physies in Europe still has quite a rosy future.

Much of the benefit of this type of conference, particularly to the younger participants, lies in the informal contacts that are made outside the framework of the lectures. The committee of the EPS recognizes that the society has a unique part to play as a forum for younger physicists to find out what is happening in physics in the wider European context. It is too early to say what the long term role of the EPs will be. There are two or three areas, however, where it is generally agreed that the society can make its influr nee felt, including, of course, the organization of conferences on a European scale. Europe may still be far from unified, but many physicists would see the natural unity of physics as allowing the world of science to gain a head start on the politicians.

The committee of the EPS also considers that it can act as a useful catalyst in forging a sensible policy for physies journals within Europe. Details of this and other administrative facets of the EPS received much attention at Florence, but the question of an official language is not settled. There is no shortage of ides: among the committee, but implementation is proving 